\title{
Intimal thickening in autogenous vein grafts in rabbits: influence of aspirin and dipyridamole
}

\author{
ANDREW J MURDAY, ANTHONY H GERSHLICK, Y DENISE SYNDERCOMBE-COURT, \\ PETER G MILLS, C TERENCE LEWIS
}

From the Departments of Cardiothoracic Surgery and Cardiology, London Hospital, London

ABSTRACT The effects of three different platelet modifying regimens on the degree of intimal thickening of autogenous vein grafts in rabbits were measured one month after operation. Dipyridamole alone $(2 \mathrm{mg} / \mathrm{kg} / 6 \mathrm{~h})$ had little effect on the intimal thickness of these rabbits compared with that of controls (mean (1 SEM) for treated animals: $72 \cdot 0(7 \cdot 9) \mu \mathrm{m}$; controls: 63.6 $(6 \cdot 0) \mu \mathrm{m})$. High dose acetylsalicylic acid $(40 \mathrm{mg} / \mathrm{kg} / 24 \mathrm{~h})$ plus dipyridamole $(2 \mathrm{mg} / \mathrm{kg} / 6 \mathrm{~h})$ increased intimal thickening significantly $(85.8(6.0) v 63.6(6.2) \mu \mathrm{m} ; \mathrm{p}=0.05, \mathrm{n}=17)$. Low dose acetylsalicylic acid $(0.5 \mathrm{mg} / \mathrm{kg} / 24 \mathrm{~h})$ plus dipyridamole $(2 \mathrm{mg} / \mathrm{kg} / 6 \mathrm{~h})$ also increased intimal thickening (79.0 $(6 \cdot 1) v 63.6(6 \cdot 0)) \mu \mathrm{m}$ but not to a significant degree. It has previously been shown in vitro that acetylsalicylic acid increases the area of an exposed subendothelial arterial surface covered by platelets. Such an effect may explain our finding of increased intimal thickening with high dose acetylsalicylic acid plus dipyridamole.

Failure of arterial autogenous vein grafts is said to occur in three time periods after operation.' Within one month of operation failure is the result of thrombosis. In the second period, from one month to three years after grafting, failures are due to intimal thickening of the vein graft wall, stenoses in the vein unrecognised at the time of operation, aneurysm, and infection. Failure beyond three years results from progression of atherosclerosis both in the native circulation and in the vein graft itself.

Intimal thickening is probably initiated by endothelial damage sustained by the vein graft during harvesting and preparation. ${ }^{23}$ Until the graft has been completely re-endothelialised, it presents in part a subendothelial surface to the blood passing across it. This may last for up to three months after operation. ${ }^{4}$ It has been demonstrated that platelets adhere to exposed subendothelium in vitro. ${ }^{56}$ It has also been shown that platelets contain a mitogenic factor that is released during activation, which stimulates vascular smooth muscle cells to proliferate. ${ }^{7}$ It would appear therefore that platelet adhe-

Address for reprint requests: Mr AJ Murday, Department of Cardiovascular Surgery, London Hospital (Whitechapel), London E1 $1 \mathrm{BB}$.

Accepted 17 January 1984 sion to the temporarily de-endothelialised portions of the surface of the vein graft may initiate intimal thickening by causing smooth muscle cell proliferation. This hypothesis is supported by the finding that the intimal thickening which follows endothelial damage to rabbits' arteries is prevented by rendering the rabbits thrombocytopenic."

A combination of the platelet modifying agents acetylsalicylic acid and dipyridamole has been shown to increase the early patency of coronary artery vein grafts by reducing the incidence of graft thrombosis. ${ }^{10}$ There have been two small experimental studies that suggest that the same combination of drugs may reduce intimal thickening of autogenous vein grafts ${ }^{112}$ and might therefore be expected to improve clinical graft patency within the second time period after operation.

We have previously shown that an autogenous graft of external jugular vein into the common carotid artery in rabbits provides an inexpensive model in which intimal thickening is consistently produced and can be accurately measured. ${ }^{13}$ This experiment was designed to differentiate the effects of three drug regimens-dipyridamole alone, dipyridamole plus low dose acetylsalicylic acid, and dipyridamole plus high dose acetylsalicylic acid-on the development of intimal thickening in such autogenous vein arterial grafts. 


\section{Methods}

\section{ANIMALS}

Young adult white lop eared rabbits were used. They were fed a standard laboratory diet and were maintained under conditions complying with Home Office standards.

\section{OPERATIVE PROCEDURE}

Anaesthesia was induced by inhaled $4 \%$ halothane in oxygen and maintainted with $2 \%$ halothane in oxygen via a face mask. A 5-6 cm longitudinal incision was made in the neck, $2 \mathrm{~cm}$ to the right of the midline. The external jugular vein was exposed, its tributaries were ligated, and a $3 \mathrm{~cm}$ length was excised. This segment of vein was irrigated with a solution of heparin sodium in $0.9 \%$ saline ( 5 units/ $\mathrm{ml}, \mathrm{pH} \mathrm{6.5)}$ and then stored at room temperature in the same solution. The ipsilateral common carotid artery was then exposed by dividing the deep cervical fascia and retracting the sternomastoid muscle laterally, and mobilised from the surrounding tissues to free a 3-4 cm length.

Heparin sodium ( 500 units diluted in $5 \mathrm{ml}$ of $0.9 \%$ saline) was administered intravenously. After a further two minutes two microvascular clamps were applied to isolate a $3 \mathrm{~cm}$ length of the common carotid artery. A longitudinal arteriotomy, about three times longer than the diameter of the artery, was made in the distal part of the isolated segment and the proximal end of the excised length of external jugular vein and the arteriotomy were anastomosed end to side. This anastomosis was performed with interrupted sutures of $10 / 0$ microvascular prolene, microvascular instruments, and an operating microscope (magnification $\times 6$ ). A second, proximal arteriotomy was made and a similar anastomosis fashioned to the other end of the segment of vein. The common carotid artery was then ligated and divided between the two anastomoses, leaving the reversed autogenous vein graft at approximately its original length. The two clamps on the common carotid artery were removed and haemostasis was secured.

\section{HISTOPATHOLOGY}

The graft, with a 3-5 mm length of common carotid artery proximally and distally, was removed by excision under general anaesthesia four weeks after the initial operation. The contralateral external jugular vein was exposed through a separate incision and a 3 $\mathrm{cm}$ length excised so that a control vein was available for examination from each animal. The ends of each excised vessel were cannulated and the vessel was irrigated with $10 \%$ formol saline. The distal cannula was then clamped and the proximal cannula was connected to a reservoir of $10 \%$ formol saline, which was raised to a height of $90 \mathrm{~cm}$ above the vessel. This is equivalent to an inflation pressure of $70 \mathrm{~mm} \mathrm{Hg}$, which is within the physiological range of blood pressure in rabbits. After eight hours' fixation, the vessel was cut into approximately equal cylindrical sections, 3-4 $\mathrm{mm}$ in length. The segments were dehydrated through graded alcohols and embedded in paraffin wax. Sections $5 \mu \mathrm{m}$ thick were cut from the distal end of each segment of vessel and stained with either haematoxylin and eosin or van Gieson's elastin stain. Selected sections were stained with Masson's trichrome stain.

By the use of an Apple II graphics tablet and a planimetric program in an Apple II system, the average intimal thickness was calculated from 12-18 measurements of intimal thickness taken at random points around the circumference of each section.

\section{ANIMAL GROUPS}

The rabbits were divided into four groups and received the drug regimens shown in the table. Dipyridamole was started 48 hours before and acetylsalicylic acid within 24 hours after operation. Both drugs were continued up to the time of death.

Dipyridamole powder was obtained from Boehringer Ingleheim PLC. Powder was dissolved in propylene glycol to obtain a concentration of 7 $\mu \mathrm{g} / \mathrm{ml}$. Claridin tablets (Nicholas PLC, $300 \mathrm{mg}$ ASA) were dissolved in water to obtain two solutions of 3 and $30 \mathrm{mg}$ acetylsalicylic acid/ml. Fresh solutions of acetylsalicylic acid were prepared each day.

\section{STATISTICAL METHODS}

The mean intimal thickness for each treated group of animals was compared with that of the untreated group with Student's two tailed $t$ test.

\section{Results}

There were 34 animals that survived the operation and therefore entered the experiment. Of the 11 untreated animals, one had a false aneurysm at the distal anastomosis and another was unsuitable for histological measurement because of poor prepara-

\section{Medication regimens}

\begin{tabular}{llll}
\hline Group & $n$ & $\begin{array}{l}\text { Dipyridamole } \\
(\mathrm{mg} / \mathrm{kg} / 6 \mathrm{~h})\end{array}$ & $\begin{array}{l}\mathrm{ASA} \\
(\mathrm{mg} / \mathrm{kg} / 24 \mathrm{~h})\end{array}$ \\
\hline A & 9 & $2 \mathrm{mg}$ & \\
B & 7 & $2 \mathrm{mg}$ & $0 \cdot 5$ \\
D & 8 & $2 \mathrm{mg}$ & 40 \\
\hline
\end{tabular}

ASA-acetylsalicylic acid. 


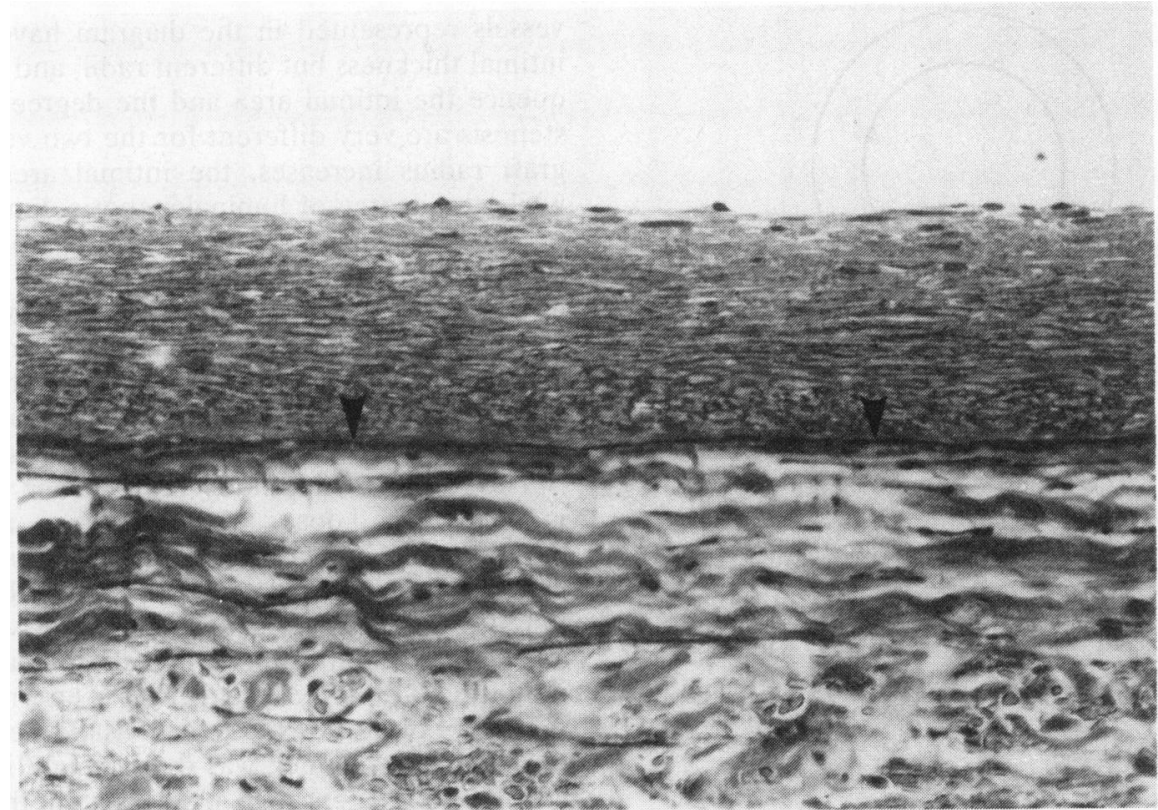

Fig 1 A vein graft one month after insertion into the arterial circulation. The internal elastic lamina (arrowed) clearly divides the cellular intima from the collagenous media. (van Gieson's elastin stain, $\times 70$.)

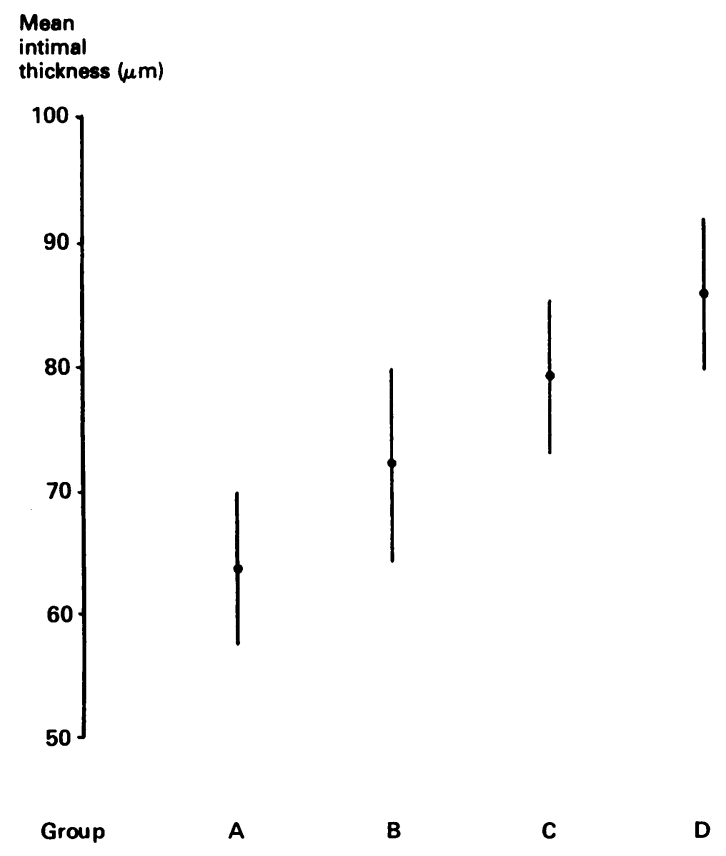

Fig 2 Intimal thicknesses (means with SEM) for the four groups of animals. tion. The numbers of animals in the four groups are shown in the table.

\section{GENERAL HISTOLOGICAL APPEARANCES}

Control veins The control external jugular veins were found to be thin walled vessels. The endothelium appeared to lie directly on the internal elastic lamina. The media was composed of a few smooth muscle cells interspersed among collagen and elastin fibres and surrounded by a loose connective tissue adventitia. There were no differences in the appearance of the vein between the four groups of animals. In particular, there was no intimal thickening in any of the veins.

Grafts The grafts were easily dissected free from the surrounding tissues, which were loosely adherent. Histologically, the adventitial layer was no different from that of the control veins. The media consisted almost entirely of collagen fibres, with a few scattered fibroblasts. Between the internal elastic lamina and the endothelium there was a variable thickness of tissue consisting of smooth muscle cells, collagen, and elastic (fig 1). There were no gross morphological differences between grafts from the four groups of rabbits.

\section{INTIMAL THICKNESS}

Within any single graft there was considerable variation in intimal thickening along its length. The inti- 

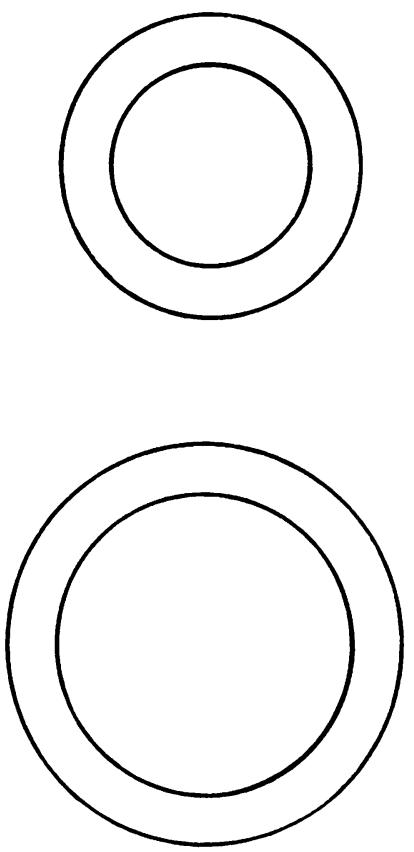

Fig 3 Diagram of the intimal layers of two hypothetical blood vessels, showing that intimal area and the stenosis resulting from intimal thickening are dependent on vessel radius as well as intimal thickness. Vessel 1: intimal thickness 1; radius 2; intimal area $5 \pi$; stenosis $56 \%$. Vessel 2: intimal thickness 1; radius 3; intimal area $7 \pi$; stenosis $44 \%$.

mal thicknesses of the grafts from each of the four groups of animals (means with 1 SEM in parentheses) were: group A $63.6(6.0) \mu \mathrm{m}$; group B 72.0 (7.9) $\mu \mathrm{m}$; group C $79.0(6.1) \mu \mathrm{m}$; group D 85.8 (6.0) $\mu \mathrm{m}$ (fig 2). There was no significant difference between the animals treated with dipyridamole alone (group B) and untreated animals (group A). The mean intimal thickness of grafts from animals treated with dipyridamole plus high dose acetylsalicylic acid (group D), however, was significantly greater than that of the controls $(p<0.05, n=17)$. The intimal thickness of grafts from animals given dipyridamole plus low dose acetylsalicylic acid (group C) was greater than that of the controls, but the difference did not reach significance.

\section{Discussion}

There are three parameters that can be used to determine the amount of intima in a cross section of a blood vessel: intimal thickness, intimal area, and the degree of luminal narrowing that results from the intimal thickening. The relationship between these parameters is illustrated in figure 3 . The two vessels represented in the diagram have the same intimal thickness but different radii, and as a consequence the intimal area and the degree of luminal $\bar{c}$ stenosis are very different for the two vessels. As a graft radius increases, the intimal area increases while the degree of luminal stenosis diminishes.

Any study which measures intimal area or degree of stenosis as the parameter of intimal thickening, but fails to take account of the normal variation in vessel size, is likely to have distorted results as a consequence. Measurement of intimal thickness, as undertaken in this study, is a direct measure of the intimal change in autogenous vein grafts.

The results of this study show that in this animal model high dose acetylsalicylic acid with dipyridamole increases intimal thickening in autogenous vein arterial grafts. Acetylsalicylic acid inhibits both prostacyclin production by vascular tissue $^{14}$ and thromboxane synthesis in platelets ${ }^{15}$ by inhibiting the cyclo-oxgenase enzyme. ${ }^{16}$ The rationale of a low dose acetylsalicylic acid plus dipyridamole regimen was that it might inhibit vascular cyclo-oxygenase to a lesser extent than platelet cyclo-oxygenase. ${ }^{17}$ In this way platelet activity would be inhibited, while vascular prostacyclin production might continue, favourably affecting the prostacyclin-thromboxane balance. ${ }^{18}$ Since, however, both the high and the low dose acetylsalicylic acid plus dipyridamole regimens increased intimal thickening in this study, it seems unlikely that any regimen will be beneficial in this respect. Dipyridamole alone had no significant effect on intimal thickening.

In vitro, it has been shown that acetylsalicylic acid either fails to influence ${ }^{19}$ or promotes ${ }^{20}$ platelet adhesion to subendothelial surfaces. Thus, while it effectively inhibits platelet thrombus formation, acetylsalicylic acid fails to prevent and may actually increase the area of an exposed subendothelial surface covered by platelets. Acetylsalicylic acid with dipyridamole has been shown to increase the early patency rates of coronary artery vein grafts, ${ }^{10}$ presumably by reducing the incidence of thrombosis in those grafts with relatively low flow rates. This study, however, suggests that the same combination of drugs, whether a high or a low dose of acetylsalicylic acid is used, increases intimal thickening, and as such is likely to reduce the patency rates of grafts at a later stage.

We would like to thank Professor CL Berry and his staff in the department of pathology at the London Hospital for their help. Dipyridamole powder was kindly supplied by Boehringer Ingleheim PLC. AJM and AHG are supported by junior research fellowships from the British Heart Foundation. 


\section{References}

' LiCalzi LK, Stansel HC. Failure of autogenous reversed saphenous vein femoro-popliteal grafting: pathophysiology and prevention. Surgery 1982;91: 352-8.

${ }^{2}$ Fontaine R, Bollack C, Winisdoerffer B, Wolf E, Briot B. Des modifications structurales de l'endothelium veineux sous l'effect de diverses agressions. Lyon Chir 1956;52:229-41.

${ }^{3}$ Baumann FG, Catinella FP, Cunningham JN, Spencer FC. Vein contraction and smooth muscle cell extensions as causes of endothelial damage during graft preparation. Ann Surg 1981;194:199-211.

${ }^{4}$ Wyatt AP, Taylor GW. Vein grafts: changes in the endothelium of autogenous free vein grafts used as arterial replacements. Br J Surg 1966;53:943-7.

${ }^{5}$ Baumgartner HR, Haudenschild C. Adhesion of platelets to subendothelium. Ann NY Acad Sci 1972;201:22-36.

${ }^{6}$ Ramirez CA, Stemerman MB, Isaacson KA, Colton CK, Smith KA, Lees RS. Morphological and morphometric characterization of platelet adhesion to the exposed subendothelium of the rabbit thoracic aorta in vivo. Microvasc Res 1981;21:320-31.

${ }^{7}$ Ross R, Glomset T, Kariya B, Harker L. A plateletdependent serum factor that stimulates the proliferation of arterial smooth muscle cells in vitro. Proc Nat Acad Sci 1974;71:1207-10.

${ }^{8}$ Rutherford RB, Ross R. Platelet factors stimulate fibroblasts and smooth muscle cells quiescent in plasma serum to proliferate. J Cell Biol 1976;69: 196-203.

${ }^{9}$ Friedman RJ, Stermerman MB, Spaet TH, Moore S, Gouldie J. The effect of thrombocytopenia on arteriosclerotic plaque formation. Fed Proc 1976; 35:207.

${ }^{10}$ Cheseboro JH, Clements IP, Fuster V, et al. A plateletinhibiting-drug trial in coronary artery bypass operations. N Engl J Med 1982;307:73-8.
${ }^{11}$ Metke MP, Lie JT, Fuster V, Josa M, Kaye MP. Reduction of intimal thickening in canine coronary bypass vein grafts with dipyridamole and aspirin. Am J Cardiol 1978;43:1144-8.

12 McCann RL, Hagen PO, Fuchs JCA. Aspirin and dipyridamole decrease in intimal hyperplasia in experimental vein graft. Ann Surg 1980;191:238-43.

${ }^{13}$ Murday AJ, Gershlick AH, Syndercombe-Court YD, et al. Intimal hyperplasia in autogenous vein grafts in rabbits - a new animal model. Cardiovasc Res 1983;17:446-51.

${ }^{14}$ Moncada S, Higgs EA, Vane JR. Human arterial and venous tissues generate prostacyclin (prostaglandin $\mathrm{X})$, a potent inhibitor of platelet aggregation. Lancet 1977; i: $18-20$.

${ }^{15}$ Burch JW, Stanford N, Majerus PW. Inhibition of platelet prostaglandin synthetase by oral aspirin. $J$ Clin Invest 1978;61:314-9.

${ }^{16}$ Roth GJ, Majerus PW. The mechanism of the effect of aspirin on human platelets. J Clin Invest 1975; 56:624-32.

${ }^{17}$ Hanley SP, Bevan J, Cockbill SR, Heptinstall S. Differential inhibition by low-dose aspirin of human venous prostacyclin synthesis and platelet thromboxane synthesis. Lancet 1981;i:969.

${ }^{18}$ Moncada S, Gryglewski R, Bunting S, Vane JR. An enzyme from arteries transforms prostaglandin endoperoxides to an unstable substance that inhibits platelet aggregation. Nature 1976;263:663-5.

${ }^{19}$ Cazenave JP, Kinlough-Rathbone R, Packman MA, Mustard JF. The effect of acetylsalicylic acid and indomethacin on rabbit platelet adherence to collagen and the subendothelium in the presence of a low or high haematocrit. Thromb Res 1978;13:971-81.

${ }^{20}$ Baumgartner HR, Tschopp TB, Weiss HG. Platelet interaction with collagen fibrils in flowing blood. II. Impaired adhesion-aggregation in bleeding disorders. A comparison with subendothelium. Thromb Haemostas 1977;37:17-28. 